\title{
Bruxas, Mito ou Realidade: A Educação Feminina no Período Medieval
}

\author{
Cheila Cristina dos Santos Teixeira ${ }^{1}$; Lireida Maria Albuquerque Bezerra ${ }^{2}$
}

\begin{abstract}
Resumo: Histórias de bruxas sempre fascinam pela magia e mistério que rodam suas figuras. Boas ou más, elas sempre fizeram parte do imaginário infantil nos mais diversos contos, passados por nossos pais e avôs de geração à geração. Quem não conhece uma boa história de bruxa ou não se lembra uma mulher feia com uma grande verruga no nariz? Contudo, será que elas realmente existiram ou foram criadas apenas com o intuito de educar através do medo, tão comum em épocas mais remotas? O presente estudo tem como objetivo elucidar o mistério envolvendo essas mulheres, voltando o olhar para a Idade Média, procurando identificá-las e por que assim eram consideradas. Através de um estudo bibliográfico o trabalho mostrará quem eram essas mulheres, que tipo de educação elas tinham e que se nos deixaram algum legado. Torna-se relevante por desmistificar a figura da bruxa como ela é conhecida nos dias atuais.
\end{abstract}

Palavras-Chave: Bruxas, Mulheres, Magia, Idade Média, Educação.

\section{Witches, Myth or Reality: Women's Education in Medieval Period}

\begin{abstract}
Witches' stories always fascinate by the magic and mystery that run their figures. Good or bad, they have always been part of the children's imagination in the most diverse tales passed by our fathers and grandfathers from generation to generation. Who does not know a good witch story or do not remember an ugly woman with a big wart on her nose? But did they actually exist or were they created solely for the purpose of educating through fear, so common in more remote times? The present study aims to elucidate the mystery involving these women, looking back to the Middle Ages, trying to identify them and why they were considered. Through a bibliographical study the work will show who these women were, what kind of education they had and what legacy they left us. It becomes relevant by demystifying the figure of the witch as it is known today.
\end{abstract}

Keywords: Witches, Women, Magic, Middle Ages, Education.

\section{Introdução}

A idade média foi um período conturbado de grandes domínios, de integração de diversos povos e culturas, destruição de outras, mas se destaca principalmente por ter sido um período de solidificação do cristianismo e da Igreja Católica. Com a forte influência da Igreja sobre as famílias dessa época, muitas viviam no sistema patriarcal de educação, onde os homens detinham o poder absoluto sobre as mulheres (pais sobre filhas, maridos sobre esposas).

\footnotetext{
${ }^{1}$ Aluna do Mestrado Internacional em Educação pela Anne SullivanUniversity. E-mail: cheila.teixeira@ hotmail.com;

${ }^{2}$ Graduada em Geografia pela Faculdade de Filosofia do Crato (1984). Especialização em Ciências na área de Concentração Geo ambiente. Mestre em Geografia pela Universidade Federal do Ceará (2013). Atualmente é professora da Universidade Regional do Cariri, no Departamento de Geociências, no Curso de Geografia, com as diciplinas: Estado, Economia e Configurações Territoriais e Geografia Cultural. Também atua na Geografia Urbana, Geologia, Geografia Regional e Didática do Ensino de Geografia. E-mail: lireida.mabe@ gmail.com.
} 
Dessa forma a educação feminina ficava limitada aos saberes domésticos como bordados, pinturas e a criação dos filhos. Hábito comum na aristocracia, esse modelo não revelava-se entre as camponesas que eram tidas como mulheres trabalhadoras, companheira de seus maridos e em alguns casos líderes de comunidades.

Contudo as camponesas nem sempre eram bem vistas. Por serem parteiras, curandeiras, conhecedoras de vários elementos da natureza, muitas vezes vitais a certas comunidades, elas eram consideradas bruxas por deterem o conhecimento de ervas, plantas, animais e a utilização da terra para curar.

Dessa forma o objeto desse estudo volta-se para as camponesas (bruxas), que viveram no período medieval, época que servirá de base para o trabalho. Ele se propõe a identificar essas mulheres, que tipo de educação elas recebiam para adquirirem conhecimento sobre os elementos da natureza e utilizá-las e o que as caracterizavam como bruxa. Baseando-se em autores como Pinsky (2015), Arruda (2001), Nogare (1985) e Cabot (1992) entre outros, o presente trabalho pretender desmistificar o papel da bruxa de criatura do mal e demoníaca, tornado-se relevante para que se conheça um pouco da vida dessas mulheres, num período em que o domínio masculino era predominante, marcado por poder e violência, bem como descobrir o possível legado deixado por elas nos dias atuais.

\section{Situando-se no Período Medieval}

A Idade Média é o período mais longo da história que vai do século $\mathrm{V}$ até o século XV. Inicia-se com a queda do Império Romano (476 d.c) e finaliza-se com a tomada de Constantinopla pelos Turcos (1453 d.c).

É conhecida como a Idade das Trevas, pois muitos a consideram como uma época de destruição da cultura greco-romana e domínio da Igreja Católica. Embora muitos acreditem que o período medieval tenha sido um período de estagnação da humanidade, foi nessa época que o pensamento filosófico de Santo Agostinho, Santo Tomás de Aquino entre outros, surgiram solidificando-se até os dias atuais.

As principais características da Idade Média são o feudalismo, a susserania, a vassalagem, as Cruzadas, as ordens de cavalaria e a peste negra. É dividida em Alta Idade Média 
(séc.V ao séc. X), Idade Média Clássica (séc.XI ao séc.XIII) e Baixa Idade Média (séc.XIV e séc.XV). Na Europa antiga, cultura, valores e povos antigos se mesclaram aos povos germânicos e constituíram uma sociedade que se expandiu por diversas partes do mundo.

A base do sistema do Império Romano era o feudalismo. Essa sociedade feudal dividia-se em dois extremos (servos e senhores): os proprietários fundiários e os camponeses. Os servos utilizavam as terras dos senhores como se fossem deles, recebendo apenas uma parte do que produziam, ficando os senhores com todo o resto. Assim os senhores do feudo exerciam um poder absoluto em seus domínios como: aplicação de leis, administração da justiça, declaração de guerras ou paz.

Contudo, a Igreja Católica era a responsável por dar ordens aos componentes nesta organização social. Ela era a maior dona de terras e controlava a vida de todos os indivíduos como nos mostra Hilário Franco em seu estudo sobre a sociedade feudo-clerical:

Em uma sociedade essencialmente agrária, a Igreja era a maior dona de terras. Destaca-se, portanto, no jogo de doação e recepção de feudos. Controla ainda as manisfestações mais intimas da vida dos indivíduos: a consciência, pela confissão; a vida sexual com o casamento; o tempo, pela imposição do calendário litúrgico; o conhecimento, com o controle das artes, das festas, do pensamento; a vida e a morte, administrando os sacramentos... (Júnior apud Arruda e Pillet 2001, p. 119)

Reis, duques, senhores feudais, todos estavam submetidos ao poder da Igreja representada pelos padres, bispos e cardeais, devido à concepção religiosa de que era preciso preocupar-se com a eternidade já que tudo é transitório, justificando assim a produção de alimentos pelos servos para sustentar o reino de Deus. Dessa forma a Igreja exercia influência em tudo: população, artes, política, cultura e religião.

Com o avanço do império Islâmico, a Igreja Católica e os reis organizaram expedições militares com o objetivo de recuperarem as terras em poder dos fiéis. Realizadas entre os séc. XI e XII as Cruzadas tinham o intuito de conquistar Jerusalém, novas terras e o domínio das rotas mercantis orientais. Com isso foi possível a expansão territorial das cidades européias, além de circulação de produtos orientais que proporcionaram as companhias mercantis, atividades comerciais, o crescimento as cidades, a expansão do mercado, a economia monetária e posteriormente o capitalismo. 
Id on Line Revista Multidisciplinar e de Psicologia

Id on Line Multidisciplinary and Psycology Journal

\section{Identificando as Bruxas}

Com o crescimento demográfico e o surgimento de novas cidades, as relações servis também mudaram. A colheita ruim, a escassez de alimentos, as cobranças de altos impostos provocaram inúmeras revoltas camponesas em diferentes regiões da Europa, denunciando a exploração que dominava os campos. Inanição, doença, pobreza era comum as sociedades europeias. A assistência médica aos pobres, mulheres e crianças era praticamente inexistente. Assim muitos homens e mulheres retiravam de suas próprias experiências com a terra meios de sobrevivência e a cura para doenças.

Nesse contexto, como se não bastasse, as mulheres eram vistas como disseminadoras do mal, pois eram a personificação do pecado devido as tentações que provocavam. Para a Igreja eram pecadoras em potencial, pois descendiam de Eva, aquela que levou Adão ao erro e em consequência a queda da humanidade, ou seja, a mulher era má por natureza e havia sido criada com a única função de procriar. Só não eram pecadoras se fossem virgens, mães, esposas ou vivessem em conventos.

Pouco se sabe a respeito da mulher medieval, visto que toda documentação da época era escrita em partes, por pessoas que constituíam a Igreja, pois elas eram o próprio mal. O próprio Santo Tomás, que valorizava o valor absoluto da pessoa, retrata a mulher como algo sem valor, sem força "para ele a mulher não passaria de um macho falido, que quando a natureza não tem força para produzir um homem forma uma mulher.” (NOGARE, 1985, p.53)

As mulheres camponesas ou de classes inferiores acompanhavam seus maridos no trabalho feudal. Mesmo viúvas ou sozinhas elas trabalhavam com os filhos para provê o próprio sustento. Além disso, trabalhavam muito, fiando, tecendo, cuidando das crianças e cultivando a terra. Muitas não seguiam os rituais da Igreja Católica. Elas cultuavam a terra e as divindades pagãs da religião Antiga. Em algumas doutrinas essa mulheres eram consideradas iguais aos homens podendo ter os mesmos direitos que eles.

O conceito de criança ou infância era inexistente. Considerados adultos em miniatura, eram tirados desde cedo do colo das mães para seguir os pais nos campos e a mães nos afazeres domésticos.

Ainda meninas aprendiam a fiar, tecer, cuidar e utilizar a terra para a cura de doenças, ou seja, aprendiam os rituais utilizando a própria natureza como poder de cura, em uma época 
de total abandono do Estado aos mais pobres. Muitas eram parteiras, curandeiras, enfermeiras e assistentes, era como se fossem as médicas de uma sociedade que se encontrava a margem, como nos mostra Michelete:

Nunca, nesse tempo, uma mulher admitiria consultar-se com um homem, entregar-se a ele, confiar-lhe todos os seus segredos. As feiticeiras examinavam-se sozinhas e foram, para as mulheres principalmente, o único médico. O que melhor sabemos da medicina aplicada pelas feiticeiras é que empregavam - para os mais variados fins, para acalmar, estimular - uma grande família de ervas, misteriosa, perigosas, mas de grande utilidade.( MICHELE apud ARRUDA E PILETTI, 2005, p. 144)

As curandeiras eram uma alternativa para aqueles que necessitavam, pois estudavam a natureza, aprendiam com as anciãs da comunidade. As bruxas praticavam cura e exerciam uma grande liderança espiritual. Essas bruxas nada mais eram que as médicas do período medieval, como afirma Angelin (2005):

\begin{abstract}
Ao analisarmos o contexto histórico da Idade Média, vemos que bruxas eram as parteiras, as enfermeiras e as assistentes. Conheciam e entendiam sobre o emprego de plantas medicinais para curar enfermidades e epidemias nas comunidades em que viviam e, conseqüentemente, eram portadoras de um elevado poder social. Estas mulheres eram, muitas vezes, a única possibilidade de atendimento médico para mulheres e pessoas pobres. Elas foram por um longo período médicas sem título. Aprendiam o ofício umas com as outras e passavam esse conhecimento para suas filhas, vizinhas e amigas.
\end{abstract}

Além disso, com a medicina ascendendo entre os jovens nobres, não era interessante para eles terem as bruxas como suas concorrentes, como observa Cabot: “... a profissão médica também se interessou na perseguição das bruxas e das curandeiras que ofereciam uma alternativa às práticas médicas ensinadas nas universidades da época.” (Cabot, 1992, p.83)

Com todo esse conhecimento e poder, sabendo exatamente a diferença entre a dose e o veneno, elas arriscavam-se muito, pois se encontrada determinadas ervas em seu poder elas corriam os risco das mortes mais cruéis pela Inquisição.

A Inquisição era uma espécie de tribunal religioso para condenar aqueles que não praticavam os dogmas da Igreja Católica, sendo considerados hereges, praticantes de bruxaria ou de outras religiões. Instituído no ano de 1233, pelo Papa Gregório IX, ela era "uma massiva campanha judicial realizada pela Igreja e pela classe dominante contra as mulheres da população rural”. (Ehrenreich\&English,1984 apud Angelin 2005). Seu objetivo era eliminar os hereges e os que não praticavam o catolicismo, pois tornavam-se uma ameaça a doutrina cristã. 
Id on Line Revista Multidisciplinar e de Psicologia

Id on Line Multidisciplinary and Psycology Journal

Calcula-se que 9 milhões de pessoas foram acusadas, julgadas e mortas, destes $80 \%$ eram mulheres, moças e meninas.

\section{Relação entre as Comunidades Pagãs, o Culto à Deusa e às Bruxas}

A integração dos povos germânicos por toda a Europa trouxe uma diversidade de culturas e religiões que coexistiram com o cristianismo durante séculos. Muitos desses grupos viviam em tribos, caçavam, pescavam, eram agricultores e pastores. A rotina das lavouras ficava a cargo das mulheres, como nos mostra Pinsky, "são elas que cuidam da casa, das crianças, da comida e da colheita, submetidas à rotina massacrante.” (Pinsky, 2015, p.54). Alguns viviam em conflitos constantes pelo domínio de terras.

Esses grupos eram politeístas, adoravam o sol, a lua e as estrelas. Cultuavam o espírito da força da Natureza que julgavam habitar às montanhas, os bosques e as águas. A chamada antiga religião era fundamentada no culto à Deusa da fertilidade, uma Grande Mãe. Esses povos cultuavam seus deuses pagãos e praticavam seus rituais, mesmo com a Igreja sempre vigilante. Para esses clãs, antigos nômades desde a época do paleolítico, tudo era mistério e o maior deles era o da fertilidade. Mesmo observando os animais que tinham seus filhotes, não tinham consciência da participação masculina na reprodução.

Dessa forma a mulher passou a ser considerada como a terra fértil, uma grande mãe, pois de tempos em tempos suas barrigas cresciam e ao final de algumas luas surgia um novo membro na tribo, sendo alimentado com o leite do seu próprio corpo, tornando-se ainda mais misteriosa ao verter sangue em alguns períodos sem morrer.

Assim essa religião cultuava a terra por sua fertilidade que tudo provê para os seus, fonte de toda a vida assim como a mulher. Com o passar do tempo os homens foram tomando consciência de sua participação na concepção, surgindo assim outros deuses.

Dessa forma essa educação era passada por gerações pelos mais velhos, solidificando cada vez mais a doutrina de culto aos deuses e a natureza. Por isso muitas mulheres foram consideradas bruxas pela prática de rituais pagãos e conhecimento da natureza.

Bruxa era o nome dado supostamente a uma mulher que tinha poderes demoníacos ou praticava magia negra e que por serem extremamente más, valiam-se de seus poderes para 
derrotar os inimigos e torturar as pessoas. No entanto muitos autores utilizam a palavra bruxa para mulheres consideradas sábias, protetoras, que conhecem e utilizam os poderes da natureza para o bem.

Segundo afirmam EHERENREICH \& ENGLISH (1984, S. 13), as bruxas não surgiram espontaneamente, mas foram fruto de uma campanha de terror realizada pela classe dominante. Poucas dessas mulheres realmente pertenciam à bruxaria, porém, criou-se uma histeria generalizada na população, de forma que muitas das mulheres acusadas passavam a acreditar que eram mesmo bruxas e que possuíam um "pacto com o demônio".(Angelin, 2005)

A palavra feiticeira tem como significado, aquela que faz feitiços, que seduz, que encanta. Dessa forma o significado de feiticeira não condiz com a caracterização da bruxa feia, horrenda, já que supõe-se que quem seduz seja extremamente bela. O esteriótipo da bruxa feia e velha se deu por conta da aparência idosa e descuidada de algumas camponesas, mas também existiam mulheres belas que de alguma forma despertava o desejo dos homens e do clérigo.

Levando-se em conta o discurso filosófico cristão da época em que a mulher era portadora do mal e de todo o pecado, descente de Eva (embora a Igreja tenha criado a redentora na figura de Maria, mulher que se torna divina através da humildade e submissão) as mulheres eram tidas como criaturas irracionais, desprovidas de pensamentos próprios, sendo então objeto de controle dos homens justificando assim sua inferioridade e fragilidade.

Por todos esses motivos as mulheres e principalmente as bruxas eram temidas e dessa maneira deveriam ser controladas para que os homens não perdessem o poder por causa de seus encantos, não fossem levados ao pecado que não os conduziriam a Deus ou a perfeição divina.

\section{O Possível Legado das Bruxas}

Diante do que foi exposto nos capítulos anteriores, as bruxas nada mais eram que camponesas sábias, com conhecimentos de ervas e plantas que utilizavam em beneficio da comunidade para a cura de diversas enfermidades, possíveis médicas.

Atualmente, na sociedade moderna, encontramos essas "bruxas", que mesmo sem conhecimento científico ou nenhum conhecimento valem-se do poder de cura das plantas para inúmeras doenças. No interior de algumas regiões do país é possível encontrar uma bruxa dos 
Id on Line Revista Multidisciplinar e de Psicologia

Id on Line Multidisciplinary and Psycology Journal

dias atuais: parteiras, benzedeiras, curandeiras que utilizam seu conhecimento para ajudar. Muitas vezes elas são a única fonte de auxilio de determinadas comunidades onde a medicina ainda falta.

O hábito de beber chás de ervas e a utilização de talismãs advém da magia das bruxas que viveram no período medieval e que de alguma forma foi incorporado ao cristianismo.

\footnotetext{
Ainda hoje é possível encontrar remanescentes da magia cristã no mundo inteiro, na forma de medalhas, escapulários, patuás, água benta, relíquias, santinhos para colocar no painel dos automóveis, e qualquer objeto bento que seja usado para proteção ou favores especiais.(CABOT, 1992, p.73)
}

As bruxas com sua compreensão a respeito da natureza deixaram seu legado no tocante a essa prática. Em épocas de aquecimento global e agressões a natureza, muita gente se volta ao cultiva de plantas, ao consumo racional da água, às idéias de sustentabilidade, à utilização de produtos naturais que beneficiam a saúde, proporcionando bem estar e vida longa.

Sem falar na procura por ambientes que propiciem a busca pela paz e tranqüilidade interior em épocas tão conturbadas e estressantes como a nossa. A ioga, a meditação, o contato direto com a natureza é simplesmente a procura do homem moderno com sua espiritualidade, o entendimento da ligação entre o homem e a natureza, atitudes que a bruxa medieval praticava ao realizar seus rituais de adoração à natureza, a Grande Deusa.

A importância de se estar ligado à natureza, retirando dela somente o necessário, retribuindo e respeitando através de suas oferendas, tão confundidos com bruxaria eram sua doutrina, sua religião, sua forma de viver. Elas compreendiam que era preciso a integração do homem a natureza e reconheciam os princípios criadores do mundo, "viver em simbiose com a natureza significa, exatamente, respeitá-la.” (Pinsky, 2015, p.46)

Dessa forma as bruxas medievais com sua arte, conhecimento e espiritualidade deixaram seu legado aos dias atuais, sejam eles em forma de chás, encontros com a natureza ou nos contos maravilhosos ouvidos desde a infância.

\section{Considerações Finais}

Apesar das inúmeras denominações, rótulos e conceitos, as bruxas tinham um vínculo com a natureza, com os deuses e com as sociedades humanas. Utilizando seu conhecimento 
Id on Line Revista Multidisciplinar e de Psicologia

Id on Line Multidisciplinary and Psycology Journal

medicinal na cura das enfermidades e epidemias das comunidades elas eram as médicas em locais marginalizados, destituídos de total assistência.

Portadoras de um grande poder social, suas práticas, conhecimentos e rituais iam sendo passados de geração a geração umas as outras.

Quando seus costumes e religião passaram a ser vistos como ameaça a doutrina cristã, ao poder da Igreja e ao Estado elas foram consideradas hereges e portadoras de todo mal: demônios que deveriam ser contidos ou exterminados. Através dos tribunais da Igreja foram perseguidas, torturadas e assassinadas por serem propensas a feitiçaria.

Em síntese, em um século de domínio dos homens e de solidificação da Igreja Católica, as mulheres ao manifestar seus conhecimentos médicos, políticos ou religiosos foram assassinadas, pois eram uma ameaça e uma afronta ao poder do homens e aos propósito da Igreja. Contudo as mulheres não se permitiram calar e continuam lutando por igualdade de gênero, social e político. Assim como inúmeras mulheres que morreram lutando por inúmeros direitos, as bruxas talvez sejam um símbolo feminista de resistência ao poder masculino e a busca pela igualdade humana.

\section{Referências}

ARRUDA, José Jobson de A. e PILETI, Nelson. Toda a história: história geral e história do Brasil. São Paulo. Editora Ática, 2001.

CABOT, Laurie. O poder da bruxa: a terra, a lua e o caminho mágico feminino. Rio de Janeiro. Editora Campus, 1992.

NOGARE, Pedro Dalle. Humanismos e Anti-humanismos: introdução a antropologia filosófica. Petrópolis, Ed. 9. Editora Vozes, 1985.

PINSKY, Jaime. As primeiras civilizações. São Paulo. 25ed. Editora Contexto, 2015.

ANGELIN, Rosangela. Revista espaço acadêmico, n 53 Outubro, 2005 Acesso em: 02 de setembro de 2015. https://espacoacademico.wordpress.com/2012/08/.../comment-page-1/ 
Id on Line Revista Multidisciplinar e de Psicologia

Id on Line Multidisciplinary and Psycology Journal

\section{Como citar este artigo (Formato ABNT):}

TEIXEIRA, C.C.S.; BEZERRA, L.M.A. Bruxas, Mito ou Realidade: A educação feminina no período Medieval. Id on Line Revista Multidisciplinar e de Psicologia, Janeiro de 2017, vol.10, n.33, Supl 2. p. 37-46. ISSN: 1981-1179.

Recebido: 06/12/2016

Aceito: $12 / 12 / 2016$ 